\title{
DISCOVERING PERSONAL MOTIVATION THROUGH NEW LEARNING
}

\section{Steve Ellwood}

\section{INTRODUCTION}

Do we wake every day with the heart-felt desire to get to work? What gives us motivation to enter the classroom to teach and learn day after day? And what incentivises our learners to do the same?

Research into 'self-determination theory' (SDT) may highlight how both intrinsic and extrinsic motivators can be used to balance the learning process. In laying the foundation for this work, Ryan and Deci (2000) state "Human beings can be proactive and engaged or, passive and submissive. Most operate as a reflection of the social conditions in which they develop and function."

Intrinsic motivation can begin with curiosity and intrigue, evolving and connecting to our desire to find answers to burning problems or issues. The extrinsic motivators may realise external reward or consequence. It is this article's contention that the extrinsic motivators in our lives help shape what we know while opening the door to new possibilities and interests. These extrinsic or external goals help to shed light on a favoured pathway to intrinsic motivation, which leads to success and personal discovery.

\section{BACKGROUND TO THE AUTHOR}

For the past ten years I have lectured in the Culinary Arts at Otago Polytechnic. I first taught through the unit standard based programmes which supported a controlled, assessment-based curriculum. I then made the transition onto the Bachelor of Culinary Arts Programme. The degree programme offers more creative, at times conceptual, project-based solutions to culinary based problems or issues.

Like many of my tertiary colleagues my personal teaching trajectory started with and was reflected in B. F. Skinner's behaviourist model of positive or negative reinforcement (Skinner, 1988).

Having grown through experience, I now see myself as a learner's facilitator, connecting more with Jean Piaget's philosophy and constructivist view where learners construct their own knowledge through their individualised experience. (www.teach-nology.com, n.d.) This shift in learning and teaching has introduced questions around personal motivation. What motivates us to learn and specifically how can both intrinsic and extrinsic motivation be maximised within the curriculum while directly motivating learners to achieve their learning outcomes? Reflecting on why, what, and how I teach, or in my case facilitate, new learning, compels me to look deeper into my students' motivation/s for, why they want to learn or engage with new knowledge.

The background above is followed by a dialogue highlighting learners' motivational transition from high school into tertiary education and beyond. The following section maps the Regulative Motivational Continuum and offers an example of how this model is shaped into the Bachelor of Culinary Arts program. Lastly the work offers an opinion on the benefit of a blended model of intrinsic and extrinsic motivation. 


\section{CONVERSATION}

The interested, intrinsically motivated learners work on tasks because they find them enjoyable. Their participation is its own reward and is not solely conditional on tangible rewards. New and personal interest motivates a learner's engagement within a subject resulting in their enhanced performance, persistence to learn and do, and extends and motivates their creativity through reflection, feedback and practice. "Interest is a powerful motivational process that energizes learning, guides academic and career trajectories, and is essential to academic success"(Harackiewicz, Smith, \& Priniski, 2016)

My seventeen-year-old daughter is in year twelve at High School and sits her NCEA exams at the end of the year. Her ambition is to graduate, enter tertiary education and become a radiologist. Her over-arching motivation for choosing this vocational pathway is to help others empathetically through her intrinsic interest in bio-symmetry, skeletal makeup and technology.

My daughter is very well versed in the makeup of credits within her curriculum subjects and through studying, the extrinsic motivators or rewards these subject specific credits will bring has fashioned an extrinsically motivated rewards pathway yielding an intrinsically motivated outcome. In my opinion this may leave a gap in the students' learning due to their focus on the required credit values as opposed to the fullness of the subject matter. What this young person does not yet realise, has been told or maybe even cares about, is the wealth of hidden interpersonal, invaluable social interaction and other learning that hides within conversation and participation in the everyday learning environment. As so eloquently stated by one of my colleagues as "hiding the veges."

The secondary school system we operate within encourages, in fact demands the gathering of extrinsic rewards (subject credits) in order to highlight a level of subjective competence. These extrinsic rewards may only prove the willingness of the learner to see a task through to its predetermined conclusion without revealing any deeper learning or wider knowledge the subject offers. This extrinsically motivated learning model forms the expectation of structure for our learners coming into tertiary education where at first only the 'what do I need to know' mentality drives their learning and may limit what may be learned.

As new learners enter their new environment within the Bachelor of Culinary Arts, motivational observations through conversation are noted by the facilitator. These observations of learner motivation may serve as an example of how both extrinsic and intrinsic motivation can open a door to a learners' previously un-tapped enthusiasm, learning and behaviour. It is worth noting at this point, learners may communicate within these conversations with a higher intrinsic motivation than they actually have, as the power relationship between the student and teacher underpins these conversations.

These observations may be viewed through a SDT lens. Experts in the field Edward Deci and Richard Ryan developed the SDT of motivation (Deci \& Ryan, 2008), dispelling the central belief that the best way to get learners to perform is to reinforce their behavior with grades, awards or accolades, they defined this as extrinsic or external motivation. Ryan and Deci describe a learner's intrinsic motivation comes from within. They explain there are internal forces that motivate us to behave in certain ways, including a person's core values and our individual sense of morality.

The observations above meet the three basic needs as specified in Ryan and Deci's SDT as:

I. Assigning learner autonomy, as defined by Ushioda (1996), is "being involved in and taking responsibility for one's learning in all its aspects." Autonomous action is also linked to learner agency. This agency can be seen as a learners independent thought process giving them the initiative and 'power to act.' Derek Wenmoth (2014) discusses learner agency in Core Education, Tātai Aho Rau. Wenmoth considers three core features in understanding learner agency. Firstly, agency involves self-regulation where the learner believes the way they learn will benefit their learning, in other words they achieve a personal sense of agency. Secondly, agency is reliant on the student's realisation they cannot work in isolation nor can they simply do what suits them at the time. It must be realised there are consequences for their decisions stemming from the way they exercise their agency. Thirdly, 
agency includes awareness and responsibility in regard to an individual's actions. "Decisions a learner makes will impact on both their own and others thinking and behaviour" (Wenmoth, 2014).

2. Ensuring Learner Relatedness or Connection, to other learners within the cohort or project. The concept of connectedness and collaboration mirrors trust and best practice and is crucial for successful outcomes. In a paper from the Education Review Office, Te Tari Arotake Matauranga states "Trust-based relationships foster connectedness and collective purpose among the members of the community of learning" (Donnelly \& Fitzmaurice, 2005).

3. Situational competence or how the learner perceives his or her level of competence within a given scenario. We all need to achieve, gain knowledge and acquire skills that develop control over tasks that are important to us.

When a learner considers their autonomy, relatedness and competence, as in my daughter's example, it may set them up with a base or scaffold to support their intrinsic or autonomous goals and outcomes.

\section{CAN WE MAP-OUT THEN IMPLEMENT MOTIVATIONAL PATHWAYS FOR OUR STUDENTS?}

We cannot simply separate an individual's motivation for learning into extrinsic and intrinsic pathways, we all constantly cross over between the two depending on the situation we face. These situations include our responsibilities within our employment or how the new learning lines up with our core values. According to Ryan and Deci (2008), it is important to differentiate between an individual's autonomous (intrinsic) and controlled (extrinsic) motivations. Autonomous motivation stems from a learner's (intrinsic) internal drive and enthusiasm but also may include extrinsic motivators as long as they align with the learner's value set and sense of self. Controlled motivation can be seen as external regulation linked to reward or punishment.

A continuum of motivation may be considered based on SDT which displays a pathway from 'amotivation' (the absence of any motivation) through to 'intrinsic motivation.' The table in Figure I below highlights the motivational continuum from amotivation or, the lack of any motivation, through extrinsic, to the preferred intrinsic, selfmotivating approach.

I. The regulating form indicates the level of regulation through the continuum from no controlled regulation through to autonomous intrinsic regulation.

2. The motivating source highlights a pathway from the amotivational impersonal to the autonomous internal motivations.

3. The 'what regulates motivation' shows the level of motivation from a non-valuing, controlled paradigm to an autonomous, inherently self-supported model.

\section{The Regulative Motivational Continuum}

Controlled
\begin{tabular}{|l|l|l|l|l|}
\hline Motivator & Amotivation & \multicolumn{2}{l|}{ Extrinsic Motivation } & Autonomous \\
\hline Regulating Form & No Regulation & External Regulation & $\begin{array}{l}\text { Personal link to } \\
\text { Regulation }\end{array}$ & Intrinsic Regulation \\
\hline Motivating Source & Impersonal & External & Somewhat Internal & Personal / Internal \\
\hline $\begin{array}{l}\text { What Regulates } \\
\text { Motivation }\end{array}$ & $\begin{array}{l}\text { Non-Valuing, } \\
\text { Incompetence, } \\
\text { No Control }\end{array}$ & $\begin{array}{l}\text { Compliance, } \\
\text { External Reward } \\
\text { or Punishment }\end{array}$ & $\begin{array}{l}\text { Personal Importance, } \\
\text { Conscious Valuing }\end{array}$ & $\begin{array}{l}\text { Interest, Enjoyment, } \\
\text { Inherent Satisfaction }\end{array}$ \\
\hline
\end{tabular}

Figure I. The Regulative Motivational Continuum. (Adapted from Ryan, R.M. \& Deci, E.L. (2000). 
The model in Figure I adapted from Ryan and Deci (2000), brings to light where there is less control or regulation in place the lower their self-motivation, whereas the more autonomous and personal the motivator appears to the learner, their motivation will be more aligned with their intrinsic motivations. If we consider a person's extrinsic and intrinsic motivation as a continuum, it follows that we cannot help but be motivated by both ends of the motivational spectrum and each will influence our behaviors and drive us to meet the three basic SDT needs of autonomy, relatedness and competence.

\section{Motivation in the Bachelor of Culinary Arts context}

\section{Controlled $\longrightarrow$ Autonomous}

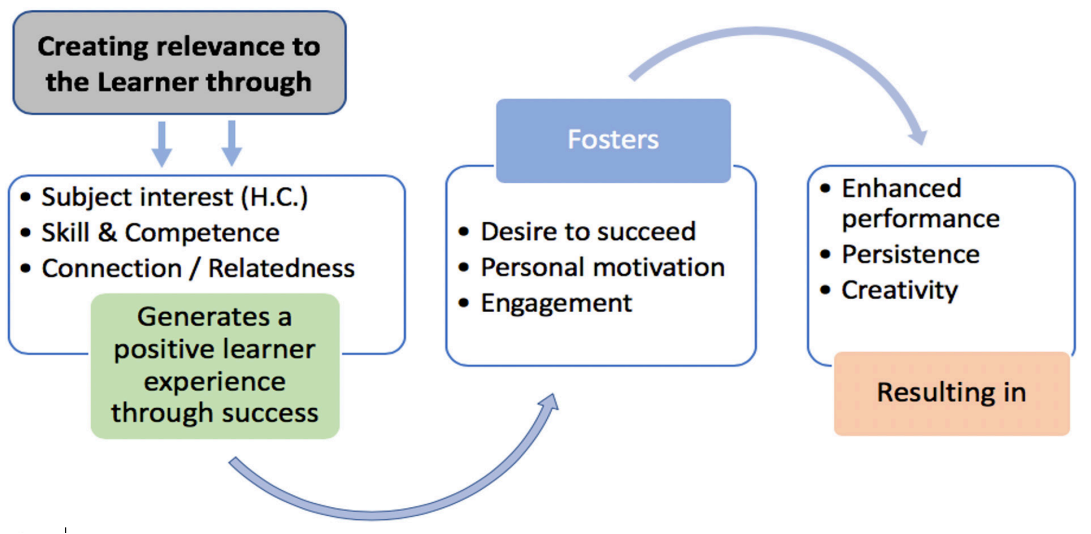

Figure 2. Motivation in the Bachelor of Culinary Arts context. Source: Author, 2019.

Within the Bachelor of Culinary Arts (BCA), consideration of a learner's extrinsic motivation in regard to subject evaluations, skills proficiency and relatedness to others is addressed. This begins (Figure 2) and includes their introduction sessions to academic rigor and assessment, skills and competence classes for theory and craft, along with curricula embedded relatedness to learner pastoral care and well-being.

This introduction lays the foundation for a positive learner experience and fosters a learner's desire to succeed. Success, however, is different for individual learners. For some, the only interest they will equate to their learning may be their extrinsically driven, hierarchical rank or position or financial success while others value the intrinsic learning or doing as their reward. 


\section{SUMMARY}

\section{Recognising both the Extrinsic and Intrinsic Motivators and Goals within our Learners}

As discussed in the previous sections, motivation may be seen on a continuum which works as a model of learning for our students. It tracks from the extrinsic, controlled motivators of regulation and compliance, shifts through and arrives at the intrinsic autonomous, individual motivators of internal regulation, interest and inherent satisfaction.

\section{Motivations and Goals}

The intrinsic motivation for participating in an activity may be its own internal reward. The activity may be fun, entertaining, satisfying or personally informative. An intrinsically motivated goal comes from within and its outcomes satisfy the psychological needs of SDT for autonomy, competence and relatedness. The extrinsic motivation for participating in an activity is to be awarded with an external reward. An extrinsically motivated goal is focused on an outcome or external gain such as money, fame, power or avoiding punishment.

In an ideal world, all learners would come equipped with their own intrinsic motivators that would drive them toward success. To help learners recognise this intrinsic motivation, it may be helpful for the learner to be guided to consider both the intrinsic or internal accolade, reward or goal that comes from within while contemplating the consequences of not completing the required task or goal.

By not looking at the extrinsic motivators in isolation or only at a learner's intrinsically constructed behaviour, both learner and facilitator may recognise that the intrinsic and extrinsic complement each other and use both to drive interest in new learning and teaching.

Steve Ellwood is a Senior Lecturer in the Bachelor of Culinary Arts programme at the Food Design Institute, Otago Polytechnic, New Zealand. As a chef and academic, Steve's primary focus is on culinary education and learner motivation. Steve has completed his Masters in Professional Practice focusing on pragmatic learning and teaching through human-centred design.

(D) https://orcid.org/0000-000I-5580-8IIX

\section{REFERENCES}

Deci, E. L., \& Ryan, R. M. (2008). Self-determination theory: A macrotheory of human motivation, development, and health. Canadian Psychology/Psychologie Canadienne, 49(3), I82-185. https://doi.org//0.1037/a00 I280 I

Donnelly, R., \& Fitzmaurice, M. (2005). Collaborative project-based learning and problem-based learning in higher education: A consideration of tutor and student roles in learner-focused strategies. In G. O'Neill, S. Moore \& B. McMullin (Eds), Emerging Issues in the Practice of University Learning and Teaching (pp 87-98). Dublin, AISHE/HEA

Harackiewicz, J. M., Smith, J. L., \& Priniski, S. J. (2016). Interest Matters: The Importance of Promoting Interest in Education. Policy Insights from the Behavioral and Brain Sciences, 3(2), 220-227. https://doi.org/l0.1177//2372732216655542

Ryan, R. M., \& Deci, E. L. (2000). Self-Determination Theory and the Facilitation of Intrinsic Motivation, Social Development, and Well-Being. American Psychologist, II.

Skinner, B. F. (1988). The selection of behavior: The operant behaviorism of BF Skinner: Comments and consequences. CUP Archive.

Ushioda, E. (1996). The role of motivation. Authentik Language Learning Resources.

www.teach-nology.com. (n.d.). Piaget's Theory on Constructivism. Retrieved April 16, 2020, from https://www.teach-nology.com/ currenttrends/constructivism/piaget/

Wenmoth, D. (2014). Learner agency » CORE Education. Core-Ed.Org. http://core-ed.org/research-and-innovation/ten-trends/20 I4/ learner-agency/ 